\title{
Instrumento de Avaliação do Software Educacional "TinkerCad": uma visão fundamentada na BNCC
}

\author{
Laís Michelle de Souza Araújo Bandeira', Nathalie Rose Ramos da Fonseca Araújo1, \\ Fernando Lucas de Oliveira Farias ${ }^{1}$, Alyana Caninde Macedo de Barros ${ }^{1}$, Janice França \\ de Queiroz $^{2}$, Isabel Dillmann Nunes ${ }^{1}$, Luiz Affonso Henderson Guedes de Oliveira ${ }^{3}$
}

${ }^{1}$ Instituto Metrópole Digital - Universidade Federal do Rio Grande do Norte (UFRN) Av. Sen. Salgado Filho, 3000 - Lagoa Nova, CEP: 59.078-970 - Natal - RN - Brasil

${ }^{2}$ Centro de Ciências da Saúde (CCS) - Universidade Federal do Rio Grande do Norte (UFRN)

${ }^{3}$ Departamento de Engenharia de Computação e Automação (DCA) - Universidade Federal do Rio Grande do Norte (UFRN)

\{bandeiralaism, nathalieroses, fernandoo.mcp, alyanamacedo\}@gmail.com, janicefq@hotmail.com, bel@imd.ufrn.br, affonso@dca.ufrn.br

Abstract. This paper proposes to construct an instrument of evaluation of educational software, prioritizing four dimensions: The General Competences of the document of the National Curricular Base (BNCC); Skills and Specific Skills for Mathematics (BNCC); Pedagogical; and, Technique. Its application consisted of a guided lesson plan, whose main objective was to allow the teacher / mediator to reflect on the teaching-learning process linked to the problematic and content and skills objectives to be developed.

Resumo. Este trabalho propõe um instrumento de avaliação de software educativo, priorizando quatro dimensões: As Competências Gerais do documento da Base Nacional Comum Curricular (BNCC); As Competências e Habilidades específicas para a área de matemática (BNCC); Pedagógica; e, Técnica. Sua aplicação consistiu num plano de aula guiado, cujo principal objetivo foi permitir que o docente/mediador reflita sobre o processo de ensino-aprendizado atrelado à problemática e aos objetivos de conteúdo e habilidades a serem desenvolvidos.

\section{Introdução}

A Base Nacional Comum Curricular (BNCC), é um documento de caráter normativo que define o conjunto de critérios de aprendizagem essenciais e de progressão, no desenvolvimento dos alunos ao longo do período escolar da Educação Básica. (BRASIL, 2017). Conforme definido na Lei de Diretrizes e Bases da Educação Nacional (LDB, Lei n ${ }^{\circ}$ 9.394/1996), a BNCC deve nortear os currículos dos sistemas e redes de ensino das Unidades Federativas como, também, as propostas pedagógicas de todas as escolas públicas e privadas de Educação Infantil, Ensino Fundamental e Ensino Médio, em todo o Brasil (BRASIL, 2017).

A Base estabelece conhecimentos, competências e habilidades que se espera que todos os estudantes desenvolvam ao longo da escolaridade básica. Orientada pelos princípios éticos, políticos e estéticos traçados pelas Diretrizes Curriculares Nacionais da Educação Básica, a BNCC soma-se aos propósitos que direcionam a educação brasileira para a formação humana integral e para a construção de uma sociedade justa, democrática e inclusiva. (BRASIL, 2017) 
VIII Congresso Brasileiro de Informática na Educação (CBIE 2019)

Anais do XXV Workshop de Informática na Escola (WIE 2019)

Com o objetivo de trazer uma proposta que traga um percurso pedagógico a ser seguido para avaliação de um software educativo. Neste trabalho, optou-se por trazer sugestões propostas para a área da matemática, do Ensino Fundamental. Para aproximar habilidades descritas na BNCC e a prática dos alunos em sala de aula, será apresentado um instrumento de avaliação do software educacional, Tinkercad, que poderá auxiliar na utilização dos conteúdos a serem desenvolvidos em sala de aula, processos e ferramentas matemáticas, incluindo tecnologias digitais. Software educativo cujo principal objetivo é o ensino ou o auto-aprendizado, contribuindo para que o aprendiz obtenha novos conhecimentos, através do seu uso.

\section{Pressupostos metodológicos}

O presente trabalho discute uma maneira alternativa na avaliação de softwares educativo, o modo como ele será utilizado e fundamentado na proposta pedagógica da matemática para a Escola (Hinostroza \& Mellar, 2001).

Modelamos o atual instrumento baseando-nos no instrumento de avaliação do software, Prancha Fácil - "Editor de Pranchas de Comunicação". É um software de Comunicação Aumentativa e Alternativa (CAA), lançado no Congresso Brasileiro de Comunicação Alternativa em junho de 2015, desenvolvido pelo Núcleo de Pesquisa em Tecnologia Assistiva - Assist UFRJ coordenado pelo Prof. Dr. Antonio Borges e pela Profa. Dra. Miryam Pelosi (NCE, 2010).

$\mathrm{Na}$ construção do novo instrumento de avaliação alguns critérios descritos acima foram excluídos, modificados e acrescidos para que o instrumento de avaliação do software educativo (SE) contemplasse as habilidades específicas de matemática, embasado na BNCC.

Aporte contemplado quanto à temática do SE no campo da BNCC: Competências gerais correlatas à temática (COMPETÊNCIA GERAL 2 e COMPETÊNCIA GERAL 5); Competência específica de matemática correlata à temática (COMPETÊNCIA ESPECÍFICA DE MATEMÁTICA 5); Habilidades específicas de matemática correlatas à temática (EF05MA14, EF05MA15, EF05MA18, EF05MA18, EF05MA18, EF01MA11, EF01MA12, EF01MA13 e EF01MA14) e Objetos de conhecimento da matemática correlatas ao $5^{\circ}$ Ano.

O instrumento de avaliação de software educativo desenvolvido, priorizou quatro dimensões, sendo estas as Competências Gerais, com embasamento na Base Nacional Comum Curricular (BNCC); as Competências e Habilidades específicas para a área de matemática, também com base na BNCC; a pedagógica; e a técnica. Sendo as dimensões pedagógica e técnica apoiadas no instrumento de Silva, 2012. Este instrumento tem como foco a avaliação de softwares educativos em matemática, seguindo as competências específicas relatadas no item 2.1 com base na BNCC. Havendo necessidade de avaliação de softwares educativos em outra área de conhecimento, é sugerido que haja a adaptação dos critérios da sessão Competências e Habilidades Específicas, seguindo a BNCC. O modelo de respostas atribuído ao instrumento, é baseado na escala de Likert (1932) que apresenta uma série de cinco proposições, sendo, para cada pergunta das dimensões citadas, as possíveis respostas: N/A (Não se aplica), A (Muito), B (Um pouco), C (Mais ou menos), D (Pouco) e E (Nem um pouco).

As dimensões do instrumento contemplam alguns critérios (objetivos), e em sua versão reduzida, é disposta em questões como: 
VIII Congresso Brasileiro de Informática na Educação (CBIE 2019)

Anais do XXV Workshop de Informática na Escola (WIE 2019)

Competências gerais: Exercita e estimula a curiosidade intelectual? Apresenta estímulo ao exercício da investigação, criatividade, hipotetização e resolução de problemas com base em conhecimentos de áreas diferentes? Possui aspectos que estimulam a crítica, reflexão, ressignificação e ética em diversas práticas sociais? Possibilita o protagonismo e a autoria na vida pessoal e coletiva ao considerar as formas de comunicação, as disseminações de informações, a produção de conhecimento e resolução de problemas?

Competências e habilidades específicas em matemática: Faz uso de processos e ferramentas matemáticas em seu uso prático a partir da prática da modelagem e resolução de problemas cotidianos ao considerar e validar estratégias e resultados? Dispõe de ferramentas que facilitem a localização de objetos no plano? Oferece estímulo para interpretação, descrição e representação da localização ou movimentação de objetos no plano cartesiano? Apresenta possibilidade de associação de figuras espaciais à suas planificações analisando, nomeando e comparando seus atributos? Reconhece, nomeia e compara polígonos ao desenhá-los utilizando o software educacional? Oferece reconhecimento da congruência dos ângulos e da proporcionalidade entre os lados de figuras poligonais ao ampliar ou reduzir as malhas quadriculadas no software educacional? Possibilita estimar, medir e comparar comprimento de lados de polígonos utilizando unidades de medida não padronizadas e padronizadas (metro, centímetro e milímetro)? Oferece recursos para descrição do objeto no espaço? Fornece a possibilidade de relacionar diferentes figuras geométricas? Disponibiliza ferramentas para nomeação das figuras planas?

Dimensão pedagógica: Possui guia de Apoio Pedagógico ao professor que o orientará na exploração do conteúdo abordado? Explicita os fundamentos pedagógicos que o embasa? Identifica os objetivos pedagógicos presentes? Possibilita uma abordagem interdisciplinar? Permite o registro de desempenho do estudante? Favorece o trabalho em grupo?

Dimensão Técnica: Possui instruções claras e objetivas para sua utilização? Possibilita acessar com facilidade todas as partes que o compõem? Fornece feedback imediato a todas as entradas de informações na interação? Permite o usuário interromper, retornar ou reiniciar uma tarefa a qualquer instante? Quando o usuário persiste em algum erro durante uma tarefa, o sistema fornece orientações? Possui ferramentas de interação como links, ícones e botões? Possui textos, hipertextos, bem distribuídos, pertinentes ao contexto, favorecedores do interesse dos estudantes que estejam utilizando o SE? Possui imagens, vídeos ou animações pertinentes ao contexto, favorecendo o interesse do usuário?

\subsection{Roteiro de Uso - Plano de Aula Guiado}

O novo instrumento de avaliação foi pensado na realidade contemporânea brasileira em vistas à implantação da Base Nacional Comum Curricular no Ensino Médio. A intenção é que este questionário sirva aos propósitos holísticos de avaliação que não tem por objetivo somente medir os conhecimentos do discente, mas se constituindo como via de aprendizado para que os conteúdos e habilidades possam ser estabelecidos.

O produto deste trabalho foi utilizado para avaliação do software TinkerCad (Prado, 2018), software de modelagem 3D livre, por dois monitores de escola de Robótica Educacional, bem como de uma pedagoga atuante em secretaria municipal de educação de município da grande Natal. Para execução deste Plano Guiado, se fez necessário o conhecimento em matemática dos seguintes tópicos: geometria espacial (sólidos geométricos, área, volume, aresta, vértice, face, raio entre outros), operações booleanas, ângulo, medida, plano cartesiano, proporção geométrica, escala, números e conversão de medidas. Também, se faz necessário o conhecimento do uso da ferramenta, noções como o agrupamento, cópia 
de modelos, sólido versus orifício, movimentação da câmera, movimento de rotação/translação/escala.

Os voluntários, ao realizarem o Plano Guiado da pesquisa/avaliação se depararam com uma problemática e um desafio a ser resolvido e, para isso, tiveram que construir o objeto do problema, utilizando o TinkerCad e as orientações do Plano Guiado. A construção do objeto no TinkerCad funcionou como auxiliar no processo de resolução do problema, permitindo a simulação de um problema real aplicado. O principal objetivo do Plano Guiado, é permitir que o docente/mediador, possa vivenciar um momento como aprendiz/aluno e assim, possa refletir sobre todo o processo de ensino-aprendizado ligado ao contexto da problemática e aos objetivos de conteúdo e habilidades a serem desenvolvidos ${ }^{1}$.

\section{Resultados}

A metodologia de avaliação de software educativo nas interfaces educativas especificamente voltadas para a aprendizagem de matemática nos fez perceber seu potencial educacional, pedagógico e interdisciplinar.

$\mathrm{O}$ perfil dos participantes de nosso experimento identificados no instrumento indica que $66,7 \%$ possuem ensino superior completo e 33,3\% cursam pós-graduação stricto sensu; as principais ocupações são Mediadores de Laboratório de Robótica Educacional e Coordenador de Gestão Escolar; 66,7\% atuam a mais de cinco anos no setor educacional, enquanto 33,3\% com experiência menor que um ano. O perfil dos participantes da avaliação do software educativo Tinkecard indica que são profissionais com experiência no setor educacional; sendo em sua maioria com formação nas áreas de ciência e tecnologia resultando em uma análise granular nos aspectos técnicos do software avaliado.

A aplicação dessa metodologia pode contribuir na prática docente permitindo focalizar o conteúdo a ser mediatizado através da tecnologia. Por fim, apresentamos uma análise quantitativa obtida com a avaliação dos três participantes voluntários, para cada dimensão. Cada cruzamento Conceito X Dimensão apresenta a quantidade de votos realizada nesta avaliação com os voluntários, como apresentado na Tabela 1.

Tabela 1. Avaliação do Software Educativo Tinkercad

\begin{tabular}{|c|c|c|c|c|c|c|c|}
\hline & $\begin{array}{l}\text { Total de } \\
\text { questões }\end{array}$ & N/A & $\mathbf{A}$ & $\mathbf{B}$ & $\mathbf{C}$ & D & $\mathbf{E}$ \\
\hline Competências Gerais & 4 & 0 & 6 & 2 & 3 & 1 & 0 \\
\hline $\begin{array}{l}\text { Competências e Habilidades } \\
\text { específicas em matemática }\end{array}$ & 10 & 1 & 21 & 7 & 1 & 0 & 0 \\
\hline Dimensão Pedagógica & 6 & 4 & 5 & 2 & 4 & 0 & 3 \\
\hline Dimensão Técnica & 8 & 1 & 11 & 3 & 4 & 0 & 5 \\
\hline
\end{tabular}

\section{Considerações Finais}

Observamos com o desenvolvimento do trabalho que faz-se necessário um olhar mais detalhado e específico para a construção de um instrumento de avaliação alinhada estrategicamente à BNCC. Por se tratar de um documento amplo e de temáticas

\footnotetext{
${ }^{1}$ Para mais informações sobre o roteiro de teste do plano de aula guiado, formulário de avaliação aplicado, resultados e fotos e vídeos de registro, acesse o diretório: https://goo.gl/CHSHmG
} 
diversificadas, os critérios devem ser adaptados aos objetivos específicos a serem atingidos em cada software. Oportuniza aos professores desenvolver atividades no ambiente escolar utilizando tecnologias no seu amplo espectro.

A possibilidade de associar à BNCC e as competências esperadas pelo software educacional "Tinkercad" amplia as possibilidades de ação do professor, explorando espaços, cultura, envolvimento e interesse do aluno. Vale salientar que outros aplicativos podem ser utilizados seguindo o percurso sugerido neste trabalho, optou-se, aqui, por utilizar o Tinkercad para efeitos de exemplificação e validação.

Os pilares da educação do século XXI incentivam o protagonismo do aluno no processo de aprendizagem e ao professor seguir à esta solicitação, que este não seja somente um transmissor do conhecimento, mas o incentivador e mediador do aprendizado do aluno.

\section{Referências Bibliográficas}

Atayde, Ana Paula Ribeiro. Metodologia de avaliação de qualidade de software educacional infantil: MAQSEI. Dissertação de mestrado. Belo Horizonte: UFMG, 2003.

BRASIL. Ministério da Educação. Base Nacional Comum Curricular, 2017. Disponível em<http://portal.mec.gov.br/conselho-nacional-de-educacao/base-nacional-comum-curricu lar-bncc>. Acesso em: 30/11/2018.

Dall'asta, Rosana J. A transposição didática no software educacional. Passo Fundo: UPF, 2004

Gomes A. S., Castro Filho J. A., Gitirana V., Spinillo A., Alves M., Melo M., Ximenes J.: Avaliação de software educativo para o ensino de matemática, WI E’2002, Florianópolis (SC).

Likert, R. A technique for the measurement of attitudes. Archives of psychology, 1932.

Oliveira, Celina C. da; Costa, José W. da \& Moreira, Mércia. Ambientes informatizados de aprendizagem: produção e avaliação de software educativo. Campinas: Papirus, 2001.

Prado, T. P. Tinkercad: ferramenta online e gratuita de simulação de circuitos elétricos.Disponível em: <https://www.embarcados.com.br/tinkercad/>. Acesso em: 19/04/2018.

Prancha Fácil. Núcleo de Pesquisa em Tecnologia Assistida da Universidade Federal do Rio de Janeiro/ NCE. Disponível em: $<$ https://sites.google.com/a/nce.ufrj.br/prancha-facil/download $>$. Acesso em: 03/12/2018.

Silva, A.C.B. Softwares Educativos: critérios de Avaliação a partir dos discursos da Interface, da Esfera Comunicativa e do Objeto de Ensino. Tese de Doutorado. Universidade Federal de Pernambuco. Programa de Pós-graduação em Educação. Centro de Educação. Recife, 2012.

Stella, A.L. et al. BNCC e a Cultura Maker: uma aproximação na área da matemática para o ensino fundamental. UNICAMP, SP, 2012. Disponível em: $<$ https://www.researchgate.net/publication/331097052_BNCC_E_A_CULTURA_MAKE R_UMA_APROXIMACAO_NA_AREA_DA_MATEMATICA_PARA_O_ENSINO_FU NDAMENTAL>. Acesso em: 03/12/2018.

Zardini, Adriana Sales. Software educativo para ensino de inglês: análise e considerações sobre seu uso. Dissertação de mestrado. Belo Horizonte: CEFET, 2009. 